\title{
Extracorporeal lung membrane provides better lung protection than conventional treatment for severe postpneumonectomy noncardiogenic acute respiratory distress syndrome
}

Manuela Iglesias, MD, a,b Philipp Jungebluth, ${ }^{\mathrm{a}, \mathrm{b}}$ Carole Petit, RN, ${ }^{\mathrm{a}, \mathrm{f}}$ María Purificación Matute, MD, ${ }^{\mathrm{c}}$ Irene Rovira, MD, ${ }^{\mathrm{c}}$ Elisabeth Martínez, MD, ${ }^{\mathrm{a}, \mathrm{b}}$ Miguel Catalan, MD, ${ }^{\mathrm{a}, \mathrm{b}}$ José Ramirez, MD, ${ }^{\mathrm{d}, \mathrm{f}, \mathrm{g}}$ and Paolo Macchiarini, MD, PhD ${ }^{\mathrm{a}, \mathrm{b}, \mathrm{e}, \mathrm{f,g}}$

From the General Thoracic Surgical Experimental Laboratory, ${ }^{\mathrm{a}}$ Departments of General Thoracic Surgery, ${ }^{\mathrm{b}}$ Anesthesiology, ${ }^{\mathrm{c}}$ and Pathology, ${ }^{\mathrm{d}}$ Hospital Clínic, Universitat de Barcelona; Ciber Enfermedades Respiratorias $^{\mathrm{e}}$; Fundació Clínic ${ }^{\mathrm{f}}$ and Institut d'Investigacions Biomèdiques August Pi i Sunyer (IDIBABS), ${ }^{\mathrm{g}}$ Barcelona, Spain.

Read at the Eighty-seventh Annual Meeting of The American Association for Thoracic Surgery, Washington, DC, May 5-9, 2007.

Received for publication May 28, 2007; revisions received Aug 1, 2007; accepted for publication Aug 27, 2007.

Address for reprints: Paolo Macchiarini, MD, PhD, Department of General Thoracic Surgery, Hospital Clinic, University of Barcelona, Villarroel, 170, 08036 Barcelona, Spain (E-mail: pmacchiarini@ub.edu).

J Thorac Cardiovasc Surg 2008;135:136271

\section{$0022-5223 / \$ 34.00$}

Copyright $\odot 2008$ by The American Association for Thoracic Surgery

doi:10.1016/j.jtcvs.2007.08.074
Objective: We compared conventional treatment with pumpless extracorporeal lung membrane (Interventional Lung Assist [iLA] Novalung; Novalung GmbH, Hechingen, Germany) support in a pig model of postpneumonectomy severe acute respiratory distress syndrome.

Methods: Adult pigs underwent a left thoracotomy without (group I) or with a left extrapericardial pneumonectomy and radical lymphadenectomy (groups II to V). After stabilization, pigs belonging to group II were observed only, whereas in those belonging to groups III to $\mathrm{V}$, a surfactant-depletion severe $\left(\mathrm{PaO}_{2} / \mathrm{FIO}_{2}<100\right)$ postpneumonectomy acute respiratory distress syndrome was induced. This was followed by observation (group III); treatment with conventional therapy including protective ventilation, steroids, and nitric oxide (group IV); or femoral arteriovenous iLA Novalung placement, near-static ventilation, steroids, and nitric oxide (group V). Each group included 5 animals. Primary outcome was extubation 12 hours postoperatively or postpneumonectomy acute respiratory distress syndrome.

Results: A severe postpneumonectomy acute respiratory distress syndrome was obtained after $9 \pm 2$ alveolar lavages over $90 \pm 20$ minutes. In group $\mathrm{V}$ pigs, the iLA Novalung device diverted $17 \% \pm 4 \%$ of the cardiac output, permitted an oxygen transfer and carbon dioxide removal of $298.4 \pm 173.7 \mathrm{~mL} / \mathrm{min}$ and $287.7 \pm 87.3 \mathrm{~mL} / \mathrm{min}$, respectively, and static ventilation (tidal volume, $2.2 \pm 1 \mathrm{~mL} / \mathrm{kg}$; respiratory rate, $6 \pm 2.9$ breaths/min). All but 1 pig belonging to group V could be extubated compared with none in groups III and IV $(P<.01)$, and only their lungs normalized cytokine release $(P<.001)$ and surfactant $(P<.03)$ and displayed fewer parenchymal lesions $(P<.05)$.

Conclusions: The pumpless extracorporeal lung membrane and near-static ventilation achieved a significantly better outcome than conventional treatment in this pig model of severe postpneumonectomy acute respiratory distress syndrome, probably because the injured lungs were not forced to work and this "rest" gave them more time to heal.

$\mathrm{P}$ ostpneumonectomy acute respiratory distress syndrome (ppARDS) is a rare ${ }^{1}$ but lethal complication. Its conventional treatment includes early intubation and mechanical ventilation (MV), diuresis to improve fluid balance, broadspectrum antibiotic coverage, aggressive pulmonary toilet including aspiration bronchoscopy and frequent position changes, as well as intravenous steroid therapy. ${ }^{2}$ Unfortunately, current mortality rates still range from $30 \%$ to $100 \%$, and most deaths are related either to the potential comorbidity or, more likely, to the further ventilatory-induced lung injury of the residual aerated and potentially recruitable lung regions. There is, therefore, a clear need for therapeutic innovations in these patients.

In a recent clinical investigation, $\mathrm{we}^{3}$ observed that the combination of a pumpless extracorporeal lung membrane (interventional lung assist [iLA] device, Novalung; 


\author{
Abbreviations and Acronyms \\ ARDS = acute respiratory distress syndrome \\ $\mathrm{AVCO}_{2} \mathrm{R}=$ extracorporeal carbon dioxide removal \\ $\mathrm{BAL}=$ bronchoalveolar lavage \\ $\mathrm{CO}=$ cardiac output \\ $\mathrm{FIO}_{2}=$ inspired oxygen fraction \\ IL = interleukin \\ iLA $\quad=$ interventional lung assist \\ MV = mechanical ventilation \\ OR = odds ratio \\ PEEP = positive end-expiratory pressure \\ ppARDS $=$ postpneumonectomy acute respiratory \\ distress syndrome \\ $\mathrm{TNF}-\alpha=$ tumor necrosis factor $\alpha$
}

Novalung GmbH, Hechingen, Germany) to near-static ventilation was able to significantly reduce the mortality rate of patients with severe ppARDS unresponsive to conventional treatment. In parallel with this, we conducted an experimental study aiming to develop a pig model of severe ppARDS and compare conventional treatment to the iLA support and static ventilation, and the results are presented here.

\section{Material and Methods}

Yorkshire Duroc pigs (Isoquimen S/L, 08080 Barcelona, Spain) weighing between 50 and $60 \mathrm{~kg}$ were used. All animals received care in compliance with the "Principles of Laboratory Animal Care" formulated by the National Society for Medical Research and the "Guide for the Care and Use of Laboratory Animals" prepared by the Institute of Laboratory Animal Resources, National Research Council, and published by the National Academy Press, revised 1996. The study was approved by the Animal Care and Use Committee of the University of Barcelona (Project N-000161399030-F).

\section{Study Design}

The experimental design is outlined in Figure 1. After instrumentation, pigs were placed in the right lateral decubitus position and randomly underwent a left thoracotomy without (group I) or with a left extrapericardial pneumonectomy and radical lymphadenectomy (groups II to V). After stabilization in the decubitus dorsalis position, pigs belonging to groups I and II were observed whereas in those belonging to groups III to $\mathrm{V}$, a surfactant-depletion ppARDS was induced followed by observation (group III), treatment with conventional therapy including protective ventilation, steroids, and nitric oxide (group IV), or femoral arteriovenous iLA placement and near-static ventilation (group V). Each group included 5 animals. Primary outcome was extubation 12 hours postoperatively or ppARDS. The observation and treatment times were 12 hours in each group, after which the animals were weaned if the following criteria were met: awakens, respiratory rate less than 30 breaths/min, $\mathrm{PaO}_{2}$ greater than $60 \mathrm{~mm} \mathrm{Hg}$, and $\mathrm{PaCO}_{2}$ less than 55 to $60 \mathrm{~mm} \mathrm{Hg}$ under pressure support ventilation with a positive end-expiratory pressure (PEEP) of $5 \mathrm{~cm} \mathrm{H}_{2} \mathrm{O}$ and a fraction of inspired oxygen
$\left(\mathrm{FIO}_{2}\right)$ of 0.4 . Otherwise, or at the first evidence of vital stress, animals were humanely killed.

\section{Anesthesia and Monitoring}

Animals were premedicated with intramuscular azaperone (4 mg/ $\mathrm{kg}$ ) and intravenous thiopental $(10 \mathrm{mg} / \mathrm{kg})$, and relaxation was induced with intravenous rocuronium $\left(6 \mathrm{mg} \cdot \mathrm{kg}^{-1} \cdot \mathrm{h}^{-1}\right)$. Orotracheal intubation was done via a $7.5 \mathrm{~F}$ endotracheal tube under bronchoscopic guidance. Animals were ventilated with volume control (Servo 900D; Siemens-Elema, Stockholm, Sweden) with the following respiratory settings: respiratory rate, 20 to 25 breaths/min; tidal volume, 10 to $12 \mathrm{~mL} / \mathrm{kg} ; \mathrm{FIO}_{2}, 1.0$, and PEEP, 5 $\mathrm{cm} \mathrm{H}_{2} \mathrm{O}$. Anesthesia was maintained via continuous infusion of fentanyl $\left(1 \mu \mathrm{g} \cdot \mathrm{kg}^{-1} \cdot \mathrm{h}^{-1}\right)$ and propofol $\left(3-5 \mathrm{mg} \cdot \mathrm{kg}^{-1} \cdot \mathrm{h}^{-1}\right)$ until the end of the study. At induction of anesthesia, intravenous cefazolin $(2 \mathrm{~g})$ was administered and every 6 hours thereafter until the end of the study. Animals were instrumented with an arterial pressure line $(5 \mathrm{~F})$ placed transcutaneously in the right femoral artery (PiCCO plus; Pulsion Medical Systems, Munich, Germany), several peripheral venous catheters, and a thermodilution catheter (Swan-Ganz catheter; Edwards LifeSciences, Munich, Germany) placed transcutaneously through the left internal jugular vein to the right retrocaval pulmonary artery under fluoroscopic guidance.

Peripheral oxygen arterial saturation and urine output were continuously monitored with a pulse oximeter (BCI Inc, Waukesha, Wis) placed at the pig's tail and a percutaneous bladder catheter, respectively. Body temperature was maintained at $37^{\circ} \mathrm{C}$ with heaters and blankets. Fluid management included continuous infusion of $0.9 \% \mathrm{NaCl}$ at a rate of $100 \mathrm{~mL} / \mathrm{h}$ with the following exceptions: (1) if mean arterial pressure was less than $60 \mathrm{~mm} \mathrm{Hg}$ or central venous pressure was less than $4 \mathrm{~mm} \mathrm{Hg}$, an additional $100 \mathrm{~mL}$ of $0.9 \%$ $\mathrm{NaCl}$ was infused over 6 minutes; and (2) if central venous pressure was greater than $8 \mathrm{~mm} \mathrm{Hg}$, the continuous infusion was stopped until it returned to within the goal range of 4 to $8 \mathrm{~mm} \mathrm{Hg}$. Postoperatively, the target overall fluid load was kept $\pm 0 \mathrm{~mL}$. Inotropic and intravenous norepinephrine $5 \mathrm{~mL} / \mathrm{h}$ was given if systemic systolic arterial pressure dropped to less than $100 \mathrm{~mm} \mathrm{Hg}$, and intravenous atropine $(0.5-1 \mathrm{mg})$ was given if heart rate was less than 50 beats/min.

\section{Surgery}

Surgical procedures were performed under sterile conditions and on the right lateral decubitus position. All animals underwent a left posterolateral muscle-sparing thoracotomy in the fourth intercostal space with or without an extrapericardial pneumonectomy and radical mediastinal lymphadenectomy. In pigs undergoing resection, the hemiazygos vein was divided and ligated to enhance exposure of the left hilum followed by division of the inferior pulmonary ligament up to the level of the inferior pulmonary vein. After intravenous administration of heparin sodium $(200 \mathrm{IU} / \mathrm{kg})$, the inferior and superior pulmonary veins were individually clamped, divided, and sutured with a running 5-0 polypropylene suture (Prolene; Ethicon, Inc, Somerville, NJ), as was the left pulmonary artery. The left main bronchus was then dissected, sectioned, and sutured with interrupted polyglactin sutures (Vicryl; Ethicon) according to the Overholt technique, and its closure was checked under a pressure of $40 \mathrm{~mm} \mathrm{Hg}$ saline. Finally, all ipsilateral lymph nodes of the upper and lower mediastinum were resected. 


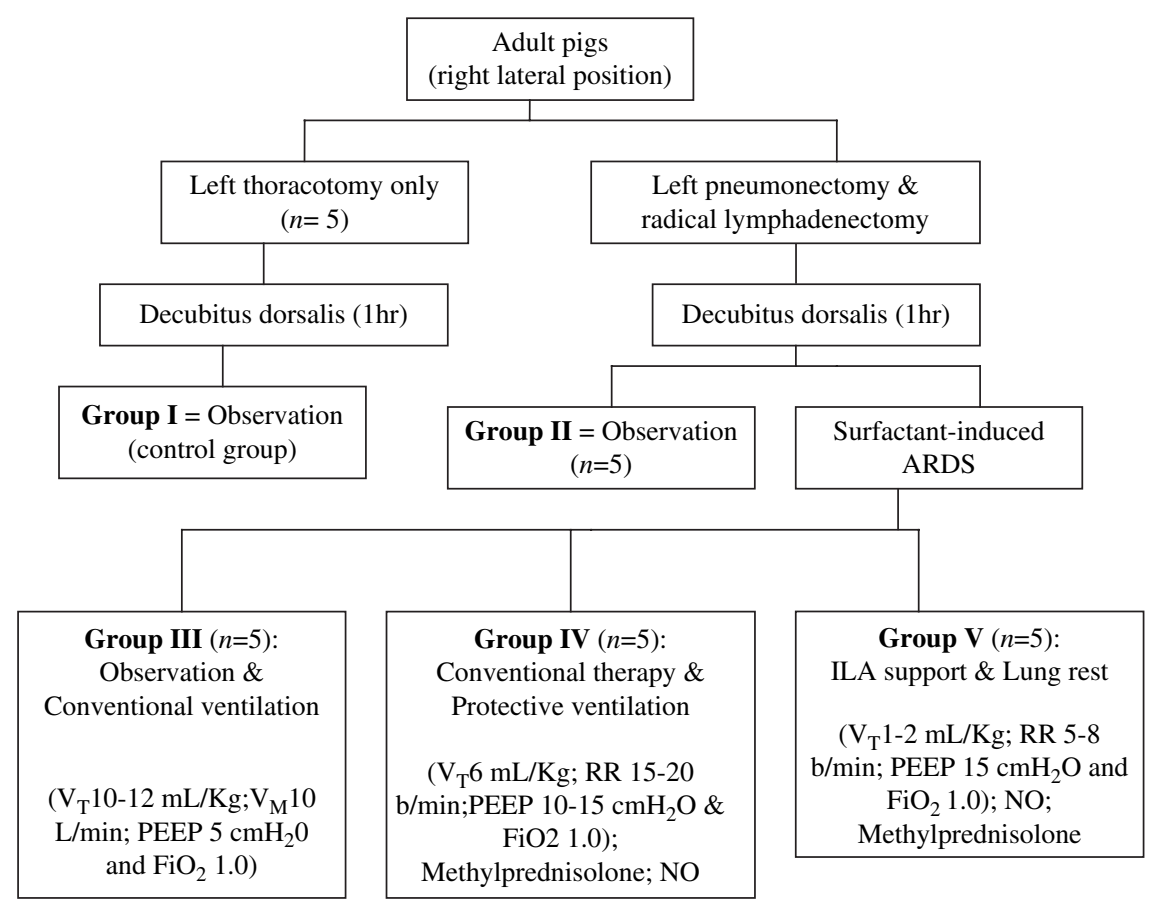

Figure 1. Study design. $V_{T}$, Tidal volume; $V M$, minute volume; $R R$, respiratory rate; $P E E P$, positive-end expiratory pressure; NO, nitric oxide; iLA, interventional lung assist device.

After detailed hemostasis, a 36F chest tube was placed through in the second intercostal space and the chest closed in layers. At the completion of the procedure, $2 \mathrm{~mL}$ of $0.25 \%$ bupivacaine hydrochloride (Bupivacaine Braun; B. Braun Medical Inc, Bethlehem, Pa) was given for a fourth intercostal nerve block. At the end of the procedure, pigs were placed in the supine position and stabilized for 1 hour.

\section{Induction of ARDS}

The commonly used surfactant-depletion model of Lachmann, Robertson, and Vogel ${ }^{4}$ was adapted to develop a ppARDS. This model reproduces arterial blood gases and radiographic and histologic changes of the lung similar to those seen in patients with ARDS. After the left pneumonectomy and lymphadenectomy, pigs were stabilized in the supine position for 1 hour. Thereafter, the endotracheal tube was disconnected from the ventilator, and prewarmed $\left(37^{\circ} \mathrm{C}\right)$ sterile saline (12-15 mL/kg per lavage) was instilled, using gravity, via the endotracheal tube into the right lung until a fluid meniscus level was seen in the endotracheal tube. After 1 minute of apnea, the fluid was gravity-drained and the recovered volume was measured. During the lavage (duration approximately 45-60 seconds), airway pressure was measured and not allowed to rise above 40 $\mathrm{cm} \mathrm{H}_{2} \mathrm{O}$. Ventilation (tidal volume $20 \mathrm{~mL} / \mathrm{kg}$, PEEP $3 \mathrm{~cm} \mathrm{H} \mathrm{H}_{2} \mathrm{O}$, respiratory rate $15-20$ breaths $/ \mathrm{min}, \mathrm{FIO}_{2}$ 1.0.) was resumed for $10 \mathrm{~min}$ utes after each lavage while $\mathrm{PaO}_{2}$ was continuously measured to assess lung injury. This procedure was repeated until a severe ARDS was evident (defined as a $\mathrm{PaO}_{2} / \mathrm{FIO}_{2}$ ratio of less than 100 after 10 minutes of ventilation after lavage), and this time point was set as the occurrence of the severe ppARDS. Subsequently, animals were randomly assigned to observation, treatment with protective ventilation or iLA, and near-static ventilation.

During the procedure, peripheral oxygen saturation was documented continuously and blood samples were continuously taken for determination of $\mathrm{PaO}_{2}, \mathrm{PaCO}_{2}$, and $\mathrm{pH}$ via conventional techniques. The criteria followed for defining an ARDS were those proposed by the American-European Consensus Conference ${ }^{5}$ in 1994 that evaluates time to appearance, oxygenation $\left(\mathrm{PaO}_{2} / \mathrm{FIO}_{2}\right.$ ratio), radiographic infiltrates, and pulmonary capillary wedge pressure. The clinical severity of the ARDS was calculated according to the definition of Murray and associates, ${ }^{6}$ which evaluates radiographic consolidation, hypoxemia, level of PEEP, and static lung compliance, whereby ARDS may be mild (1-2.5) or severe $(>2.5)$.

\section{iLA Implantation Technique}

The iLA device was placed via transcutaneous Seldinger technique, cannulating first the femoral artery and then the ipsilateral vein with Novalung arterial $(15 \mathrm{~F})$ and venous $(17 \mathrm{~F})$ cannulas, respectively. Cannulas were advanced maximally, flushed with a bolus of about $50 \mathrm{~mL}$ of heparinized saline (heparin doses $10-20 \mathrm{IU} / \mathrm{kg}$ body weight), and clamped proximally. The deaired and filled (240 mL of saline) iLA device was then connected to both previously placed cannulas after complete deairing of the connecting lines. Before declamping, all connections were secured. The iLA was declamped gently and progressively over 1 to 2 minutes to minimize the hemodynamic effects of the induced femorofemoral arteriovenous shunt.

An oxygen supply line was connected to the inflow site of the membrane oxygenator with oxygen flow of 6 to $12 \mathrm{~L} / \mathrm{min}$. A bidirectional ultrasonic flow probe sensor (Novalung Emtec) placed at the outflow venous line monitored device flow. Device functional control was achieved through a monitor (Blood Flow Monitor; Novalung) that calculates blood flow through the system using the ultrasonic flow probe. Malfunction of the iLA was defined as a driving blood flow of less than $0.5 \mathrm{~L} / \mathrm{min}$. The systemic arterial organ perfusion had to maintain $100 \mathrm{~mm} \mathrm{Hg}$ pressure, eventually with 
the aid of vasoactive drugs, as well as an activated clotting time of approximately 180 to 200 seconds with heparin if necessary.

The capability of the iLA to provide additional oxygen was measured by calculating the oxygen content of blood entering and exiting the device and multiplying the difference by the flow rate through the device, according to the following formula: Oxygen transfer $(\mathrm{mL} / \mathrm{min})=([$ Oxygen content as volume percent $] \times 10$ $\mathrm{dL} / \mathrm{L}) \times$ iLA flow rate $(\mathrm{L} / \mathrm{min})$.

Arteriovenous extracorporeal carbon dioxide removal (AV$\mathrm{CO}_{2} \mathrm{R}$ ) provided by the iLA was calculated as follows: $\mathrm{AVCO}_{2} \mathrm{R}$ $(\mathrm{mL} / \mathrm{min})=$ Carbon dioxide content in the inflow arterial cannula Carbon dioxide content in the venous outflow cannula (mL carbon dioxide/100 $\mathrm{mL}$ blood $) \times$ Blood flow iLA $(\mathrm{L} / \mathrm{min}) \times 10$.

\section{E-Hemodynamic and Lung Function}

The following hemodynamic variables were measured at baseline, during left pneumonectomy, at induction of the ppARDS, and hourly until the end of study (Monitor Hewlett-Packard model 685; Hewlett-Packard Company, Palo Alto, Calif): heart rate, cardiac output (CO), cardiac index, mean arterial pressure, mean pulmonary arterial pressure, pulmonary capillary wedge pressure, central venous pressure, systolic index, systolic volume, systemic vascular resistance, pulmonary vascular resistance, left ventricular systolic work, right ventricular systolic work, mixed venous oxygen saturation, and body temperature through the Swan-Ganz cathether.

PiCCO measured extravascular lung water volume, ventricular contractibility, and permeability vascular pulmonary index. Ventilator parameters, including minute volume, tidal volume, lung compliance, and peak airway inspiratory pressure, as well as arterial blood gases, were evaluated hourly.

\section{E-Lung Cytokine Assays and Surfactant evaluation}

The right lung was washed with $40-\mathrm{mL}$ aliquots of sterile saline solution $(0.9 \% \mathrm{NaCl})$ instilled through the bronchoscope's channel and subsequently aspirated manually before intubation and every hour thereafter. Tumor necrosis factor $\alpha(\mathrm{TNF}-\alpha)$ and interleukin (IL) 6 and 8 levels were measured in bronchoalveolar lavage (BAL) supernatants by using an enzyme-amplified sensitivity immunoassay based on the quantitative immunometric sandwich enzyme immunoassay technique (Medgenix Diagnostics, Fleurus, Belgium, and PerSeptive Biosystems, Inc, Framingham, Mass). At the same time, we assessed surfactant measurements in BAL by fluorescence polarization based on the quantitative lecithin/albumin ratio (TDx/TDxFLx Fetal Lung Madurity II; Abbott Laboratories, Chicago, Ill). Normal concentration ranges in our laboratory are as follows: TNF- $\alpha(25-120 \mu \mathrm{g} / \mathrm{mL})$, IL-6 $(<39 \mu \mathrm{g} / \mathrm{mL})$, IL-8 $(<62 \mu \mathrm{g} / \mathrm{mL})$, and mature surfactant $(>40 \mathrm{mg} / \mathrm{g})$.

\section{E-Histopathologic Features}

Animals were humanely killed 12 hours postoperatively or after ppARDS or if the animal's condition was deteriorating. Death was induced by an intravenous bolus of fentanyl, propofol, and potassium chloride $(40 \mathrm{mEq})$. Systemic heparin $(100 \mathrm{IU} / \mathrm{kg}$ ) was also given to avoid postmortem thrombus formation. The lung tissue samples of each lobe were dissected, placed in formalin for 24 hours, and embedded in paraffin overnight. The paraffin blocks were cut in sections measuring $5 \mu \mathrm{m}$, mounted on glass slides, and stained with hematoxylin and eosin. Each section was evaluated to search for des- quamation of bronchial and bronchiolar epithelium. We also sought the presence of hyaline membranes and accumulations of pyknotic cells in preterminal air spaces or recent peribronchial inflammatory changes, characterized by edema and infiltration of polymorphonuclear leukocytes and eosinophils. Accordingly, a histologic classification of the ppARDS was developed that takes into account the severity and extent of the encountered lesions (Table E1).

\section{Statistical Analysis}

Continuous variables were compared by independent-samples $t$ test. To perform between-groups comparisons of categorical variables, we calculated the odds ratio. Results are presented as mean \pm standard error of mean. Analyses were made with the SPSS package (version 7.0; SPSS, Inc, Chicago, Ill).

\section{Results}

Thirty-one animals were necessary to complete the 25-animal study; 6 either died during surgery $(n=1)$ or did not hemodynamically tolerate the lavages $(n=5)$. Pneumonectomyonly pigs had a significantly $(P<.05)$ lower $\mathrm{CO}$ and higher systemic and pulmonary vascular resistances than did the thoracotomy-alone pigs. The volume of saline instilled and necessary to obtain a severe ppARDS in pigs belonging to groups III to $\mathrm{V}$ was $9.25 \pm 1.73 \mathrm{~L}$ given via $9 \pm 2$ lavages and over $90 \pm 20$ minutes and was associated with a significant respiratory and hemodynamic deterioration compared with pigs belonging to groups I and II; there were, however, no severity differences in the ppARDS pigs (Table 1). The volume of saline returned was $9.15 \pm 1.5 \mathrm{~L}$, with a positive balance of $100 \pm 35 \mathrm{~mL}$.

The iLA diverted $1.3 \pm 0.2 \mathrm{~L} / \mathrm{min}$ or $16.8 \% \pm 4.5 \%$ of the $\mathrm{CO}$, but the resulting arteriovenous shunt effect was well tolerated clinically in pneumonectomized pigs (Table E2). The iLA device allowed an oxygen transfer and carbon dioxide removal $\left(\mathrm{AVCO}_{2} \mathrm{R}\right)$ of $298.4 \pm 173.7 \mathrm{~mL} / \mathrm{min}$ and $287.7 \pm$ $87.3 \mathrm{~mL} / \mathrm{min}$ (Figure E1), respectively; consequently, the respiratory settings of $\mathrm{MV}$ in iLA-supported pigs could be significantly lowered to reach near static ventilation (tidal volume, $2.2 \pm 1 \mathrm{~mL} / \mathrm{kg}$; respiratory rate, $6 \pm 3$ beats $/ \mathrm{min}$ ). The combination of iLA and near-static ventilation resulted in a significantly better and early recovery of the respiratory and mechanical functions of the injured lung, tissue perfusion, and oxygenation compared with group III and IV pigs (Table 2).

As expected, pigs belonging to groups I and II could be extubated. None of the animals belonging to groups III and IV could be weaned; they died within $3 \pm 1$ and $10 \pm 2$ hours, respectively, of progressive respiratory failure $(P<$ $.01)$. Four $(80 \%)$ of the 5 pigs treated with iLA and near-static ventilation fulfilled the extubation criteria $(P<.01)$ and could be weaned; none of the pigs belonging to group III or IV survived. At planned death or extubation, pigs belonging to group $\mathrm{V}$ had a significantly less severe Murray score than pigs belonging to groups IV and III $(P<.05)$ (Figure 2) The postmortem specimen, group V treated lungs 
TABLE 1. Respiratory and hemodynamic differences between the various groups of pigs

\begin{tabular}{|c|c|c|c|c|c|c|}
\hline Variables & Group I & Group II & Group III & Group IV & Group V & $P$ value \\
\hline Lavages (No.) & - & - & $9 \pm 2$ & $8 \pm 1$ & $9 \pm 2$ & NS \\
\hline Onset ppARDS (min) & - & - & $90 \pm 10$ & $90 \pm 15$ & $90 \pm 20$ & NS \\
\hline $\mathrm{PaO}_{2} / \mathrm{F}_{10}{ }_{2}$ ratio & $411 \pm 90$ & $341 \pm 94^{*}$ & $81.3 \pm 8.7$ & $86.6 \pm 19.6$ & $86.4 \pm 4.2$ & .001 \\
\hline $\mathrm{PacO}_{2}(\mathrm{~mm} \mathrm{Hg})$ & $36 \pm 5$ & $38 \pm 7^{*}$ & $63.9 \pm 7.5$ & $57.1 \pm 9.26$ & $63.6 \pm 13.9$ & .02 \\
\hline $\mathrm{sLC}\left(\mathrm{mL} / \mathrm{cm} \mathrm{H} \mathrm{H}_{2} \mathrm{O}\right)$ & $60 \pm 2.5$ & $57 \pm 4^{*}$ & $19.7 \pm 5.5$ & $20 \pm 3.2$ & $21 \pm 2.1$ & .05 \\
\hline $\mathrm{CO}(\mathrm{L} / \mathrm{min})$ & $5.6 \pm 1.5$ & $4 \pm 1.2$ & $5.7 \pm 2$ & $6.4 \pm 1$ & $6.4 \pm 2$ & .05 \\
\hline MAP (mm Hg) & $79 \pm 16$ & $81 \pm 6$ & $86 \pm 2$ & $71 \pm 7$ & $70 \pm 2$ & NS \\
\hline MPAP (mm Hg) & $26 \pm 3.6$ & $30.4 \pm 4.7$ & $40.5 \pm 6$ & $39 \pm 7$ & $37.5 \pm 8.3$ & NS \\
\hline SVR (dynes/cm ${ }^{5}$ ) & $1031 \pm 422$ & $1405 \pm 456^{*}$ & $772 \pm 522$ & $748 \pm 94$ & $662 \pm 236$ & .05 \\
\hline PVR (dynes/cm ${ }^{5}$ ) & $157.7 \pm 38$ & $354.5 \pm 126$ & $478 \pm 147$ & $304 \pm 45.4$ & $270 \pm 72.8$ & NS \\
\hline PCWP $(\mathrm{mm} \mathrm{Hg})$ & $15 \pm 2$ & $13.5 \pm 1.6$ & $12.5 \pm 2.5$ & $13.2 \pm 3.5$ & $13.2 \pm 3.1$ & NS \\
\hline Dpmax $(\mathrm{mm} \mathrm{Hg})$ & $531 \pm 161$ & $461 \pm 207$ & $510 \pm 256$ & $986 \pm 310$ & $1093 \pm 383$ & NS \\
\hline PVPI & $2.5 \pm 0.8$ & $1.9 \pm 0.4$ & $5.9 \pm 3.1$ & $4.6 \pm 2.4$ & $4 \pm 0.5$ & .01 \\
\hline $\mathrm{SvO}_{2}(\%)$ & $75 \pm 4.3$ & $80 \pm 8^{*}$ & $63 \pm 1$ & $61 \pm 4$ & $65.5 \pm 2$ & .05 \\
\hline Murray score & 0 & 0 & $3.6 \pm 0.5$ & $3.6 \pm 0.5$ & $3.6 \pm 0.5$ & $<.05$ \\
\hline
\end{tabular}

Respiratory and hemodynamic differences between various groups of pigs: Group I, Pigs treated with left thoracotomy alone without left pneumonectomy and radical lymphadenectomy; group II, pigs treated with left thoracotomy with left pneumonectomy and radical lymphadenectomy; group III, pigs treated like group II plus a surfactant depletion of the residual right lung without any further treatment; group IV, treatment with protective ventilation; group $V$, treatment with extracorporeal lung membrane and near-static ventilation. NS, Not significant; $\mathrm{PaO}_{2} / \mathrm{FlO}_{2}$, arterial oxygen tension/fraction of inspired oxygen; $P$ aco ${ }_{2}$, arterial carbon dioxide tension; $s L C$, static lung compliance ([Tidal volume/End-expiratory plateau pressure] - PEEP); $C O$, cardiac output; $M A P$, mean arterial pressure; MPAP, mean pulmonary arterial pressure; SVR, systemic vascular resistance; $P V R$, pulmonary vascular resistance; $P C W P$, pulmonary capillary wedge pressure; Dpmax, ventricular contractibility; PVPI, permeability vascular pulmonary index; $\mathrm{SvO}_{2}$, mixed venous oxygen saturation; Murray score, severity of ARDS ( $0=$ no distress; $0.1-2.5=$ mild; $>2.5=$ severe $)$. Data were collected and compared at induction of ARDS. *Indicates significance between groups III/IV and V.

had a lower dry/net weight ratio (222 vs 320 vs $343 \mathrm{~g})$ and significantly $(P<.05)$ less severity and extent of ARDS lesions than pigs treated conventionally (Table 3 ).

The injured lungs released significantly $(P<.001)$ more cytokines during induction of the ppARDS (Figure 3 ). Lung cytokines normalized during the treatment period only in iLA-treated pigs but not in those managed with observation and protective ventilation or conventional treatment $(P<.05)$ (Figure 4). Table E3 outlines the evolution of the different lung cytokines TNF- $\alpha$, IL-6, and IL- 8 over time. The quantification of the depletion of the surfactant, as pointed out in Figure 5, clearly shows that near-static ventilation allowed a significantly better recovery of the surfactant than protective ventilation.

\section{Discussion}

The surfactant depletion model of Lachmann, Robertson, and Vogel ${ }^{4}$ used in this study to obtain a severe ppARDS was chosen for two reasons: (1) it induces lung failure before the development of parenchymal remodeling and/or fibrosis takes place, similarly to what is observable in neonatal respiratory distress syndrome and in early acute lung injury in

TABLE 2. Respiratory, gas exchange, and lung compliance variables in ppARDS pigs treated with observation only (group III), protective ventilation (group IV), or extracorporeal lung membrane (iLA) support (group V)

\begin{tabular}{lccrr}
\hline \multicolumn{1}{c}{ Variables } & Group III & Group IV & Group V & P value \\
\hline Tidal volume $(\mathrm{mL})$ & $590 \pm 57.4$ & $373 \pm 46.4$ & $131 \pm 40^{*}$ & $<.001$ \\
Respiratory rate $(\mathrm{bpm})$ & $17 \pm 2$ & $19.5 \pm 0.8$ & $6 \pm 3^{*}$ & $<.001$ \\
Minute volume $(\mathrm{L} / \mathrm{min})$ & $10.4 \pm 0.5$ & $7.7 \pm 1.1$ & $1.1 \pm 0.7^{*}$ & $<.001$ \\
End-inspiratory plateau pressure $\left(\mathrm{cm} \mathrm{H}_{2} \mathrm{O}\right)$ & $37 \pm 5.8$ & $32 \pm 6.7$ & $23.7 \pm 2.1^{*}$ & $<.001$ \\
$\mathrm{PEEP}\left(\mathrm{cm} \mathrm{H}_{2} \mathrm{O}\right)$ & 5 & $11.6 \pm 2.1$ & $19.5 \pm 1.8^{*}$ & $<.001$ \\
$\mathrm{PaO}_{2} / \mathrm{F}_{2} \mathrm{O}_{2}$ ratio & $63 \pm 16$ & $180 \pm 87$ & $235 \pm 78^{*}$ & $<.001$ \\
Paco $(\mathrm{mm} \mathrm{Hg})$ & $75 \pm 4$ & $93.3 \pm 28$ & $61 \pm 14^{*}$ & $<.001$ \\
Mixed venous oxygen saturation $(\%)$ & $53.3 \pm 14$ & $74.2 \pm 9$ & $83 \pm 5.5^{*}$ & $<.001$ \\
Static lung compliance $\left(\mathrm{mL} / \mathrm{cm} \mathrm{H}_{2} \mathrm{O}\right)$ & $19 \pm 4$ & $20 \pm 7$ & $46 \pm 28^{*}$ & $<.001$ \\
\hline
\end{tabular}

ppARDS, Postpneumonectomy acute respiratory distress syndrome; $\mathrm{PaO}_{2} / \mathrm{FlO}_{2}$, arterial oxygen tension/fraction inspired oxygen; $\mathrm{PacO}_{2}$, arterial carbon dioxide tension; lung compliance was calculated as ([Tidal volume/End-inspiratory plateau pressure] - Positive end-expiratory pressure). *Statistically significant difference. Comparison was made between groups V and III/IV. 

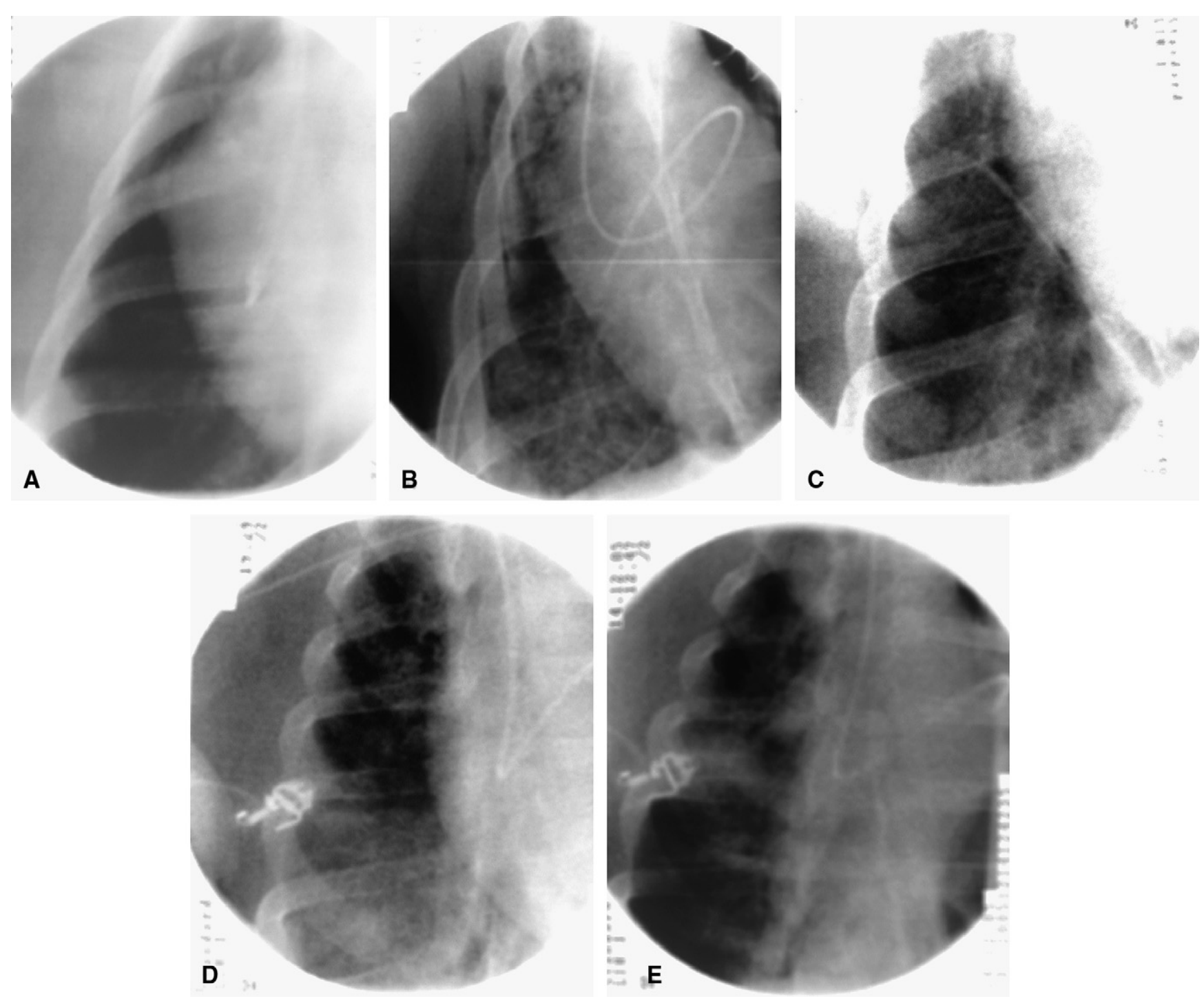

Figure 2. Selective chest $x$-ray of the right lung taken in pigs instrumented with left pneumonectomy and radical lymphadenectomy without (A, 12 hours postoperatively; Murray score: 0 ) or with surfactant depletion of the right lung $(B$, at the onset of a severe postpneumonectomy acute respiratory distress syndrome (ppARDS); Murray score: $3.6 \pm 0.5$ ) observed only (C, 3 hours postoperatively), treated with conventional treatment (D, 6 hours ppARDS; Murray score: $2.2 \pm 0.5$ ) or extracorporeal lung membrane (E, 12 hours ppARDS; Murray score: $1 \pm 0.5)$. The severity of the ARDS was calculated according to Murray and associates ${ }^{6}$ and evaluates radiographic consolidation, hypoxemia, level of PEEP, and static lung compliance, whereby ARDS may be absent (0) mild (1-2.5), or severe (>2.5).

adults; (2) it represents a suitable platform for ventilating injured lungs with high PEEP and low tidal volume. ${ }^{7}$ This ppARDS investigation was made in adult pigs and thus cannot be directly extrapolated to the clinical setting. With that stated, however, this model does mimic most of the conditions encountered in patients with severe ppARDS, ${ }^{3}$ and it provides evidence that a therapeutic strategy prioritizing a maximal reduction (tidal volume $1-2 \mathrm{~mL} / \mathrm{kg}$; respiratory rate 5-8 beats/min) of the alveolar ventilation is associated with a significantly better prognosis than established protective ventilation settings (tidal volume $6 \mathrm{~mL} / \mathrm{kg}$; respiratory rate $15-20$ beats/min).

A severe ppARDS was observed within 2 hours of depleting the surfactant of the residual right lung, and the presented data showed that it manifested itself constantly with a profound hypoxia of noncardiac origin, acute and persistent pulmonary inflammation with increased vascular permeability, and diffuse infiltrates demonstrable on chest 
TABLE 3. Severity and extend of ARDS lesions between pigs treated with left thoracotomy (group I) or pneumonectomy alone (group II), depletion of surfactant followed any further treatment (group III), conventional treatment (IV) or extracorporeal lung membrane and near-static ventilation (group V)

\begin{tabular}{lcccccc}
\hline & Group I & Group II & Group III & Group IV & Group V & P value \\
\hline No. of survivors (\%) & $5 / 5(100 \%)$ & $5 / 5(100 \%)$ & $0 / 5(0 \%)$ & $0 / 5(0 \%)$ & $4 / 5(80 \%)^{*}$ & $<.001$ \\
Survival (h) & 12 & 12 & $3 \pm 1$ & $10 \pm 2$ & $12^{*}$ & $<.05$ \\
Extubation (\%) & $100 \%$ & $100 \%$ & $0 \%$ & $0 \%$ & $80 \%$ & $<.001$ \\
Lung histology (grading, 0-3): & & & & & & \\
$\quad$ Atelectasis & $0.2 \pm 0.1$ & $0.2 \pm 0.4$ & $1.2 \pm 0.4$ & $1.4 \pm 0.5$ & $0.4 \pm 0.3$ & $\mathrm{NS}$ \\
$\quad$ Bronchial epithelium desquamation & $0.2 \pm 0.1$ & $0.2 \pm 0.1$ & $1.4 \pm 0.5$ & $1.2 \pm 0.4$ & $1 \pm 0.7$ & $\mathrm{NS}$ \\
$\quad$ Hyaline membranes & 0 & 0 & $1.4 \pm 0.5$ & $2.2 \pm 0.8$ & $0.4 \pm 0.2^{*}$ & $<.01$ \\
$\quad$ Exudative interstitial lesions & $0.2 \pm 0.1$ & $0.2 \pm 0.1$ & $2 \pm 0.7$ & $2 \pm 1$ & $1 \pm 0.7^{*}$ & .03 \\
$\quad$ Exudative alveolar lesions & $0.2 \pm 0.1$ & $0.2 \pm 0.1$ & $2.2 \pm 0.8$ & $1 \pm 0.7$ & $0.8 \pm 0.5^{*}$ & $<.03$ \\
$\quad$ Total severity grading & $0.16 \pm 0.1$ & $0.16 \pm 0.1$ & $1.6 \pm 0.6$ & $1.6 \pm 0.6$ & $0.7 \pm 0.4^{*}$ & $<.05$ \\
Severity of extension lesions (grading, 0-3) & $0.4 \pm 0.1$ & $0.2 \pm 0.1$ & $2.4 \pm 0.8$ & $2.2 \pm 0.4$ & $1.4 \pm 0.8$ & NS \\
\hline
\end{tabular}

ARDS, Adult respiratory distress syndrome; $N S$, not significant. *Indicates significance $(P<.05)$ between group IV and V.

radiographs in all animals. The learning curve of the model was very important and mostly related to the hemodynamic instability observed during the depletion of the surfactant. We found that the instillation of the prewarmed saline via the endotracheal tube was better tolerated hemodynamically if adapted to the degree of peripheral arterial saturation recovery, level of percutaneous carbon dioxide, and rise of mean pulmonary artery pressure reached after each lavages rather than the given amount of saline. Practically, it would be better to deliver one or two lavages more rather than take

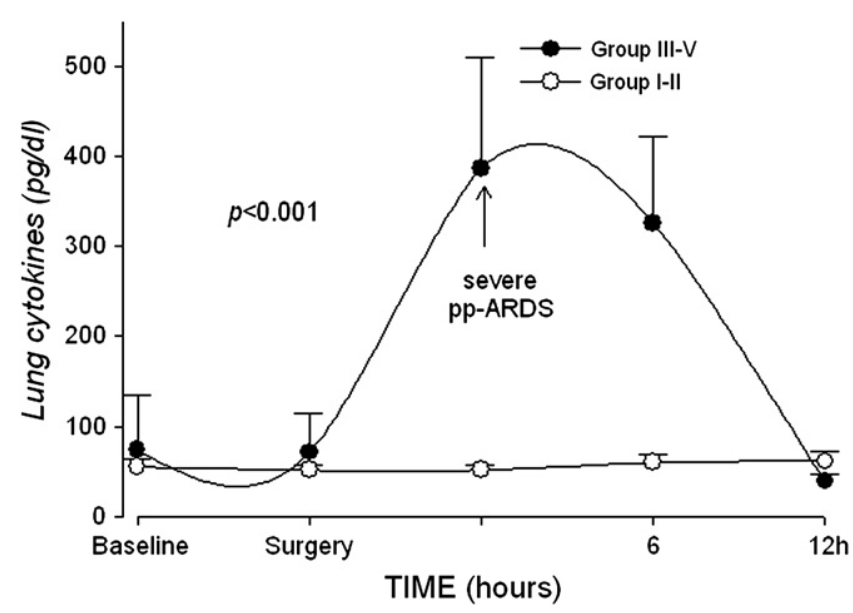

Figure 3. Dynamic of the cytokines (IL-6, IL-8, and TNF- $\alpha$ ) release of the right lung in pigs treated with left thoracotomy alone (group I), pneumonectomy with radical lymphadenectomy alone (group II), or depletion of surfactant of the right lung followed any further treatment (group III), conventional treatment (IV), or extracorporeal lung membrane and near-static ventilation (group $V$ ). The significant $(P<.001)$ increase observed in group III was observed especially during the first hour. Normal concentration ranges in our laboratory are as follows: TNF- $\alpha(25-120 \mu \mathrm{g} / \mathrm{mL})$, IL-6 (<39 $\mu \mathrm{g} / \mathrm{mL})$, and IL-8 (<62 $\mu \mathrm{g} / \mathrm{mL})$. the risks to have a hemodynamic (and respiratory) unresponsive failure.

The pathophysiologic mechanisms by which surfactant depletion, documented by the dramatic fall of surfactant in the BALs, resulted in a severe ARDS of the residual lung may have occurred because surfactant depletion increased alveolar surface tension, decreased negative pressure surrounding the alveolar vessels, and this in turn increased transmural pressure, fluid filtration, and endothelial and alveolar epithelial permeability. ${ }^{8}$ These working hypotheses are indirectly

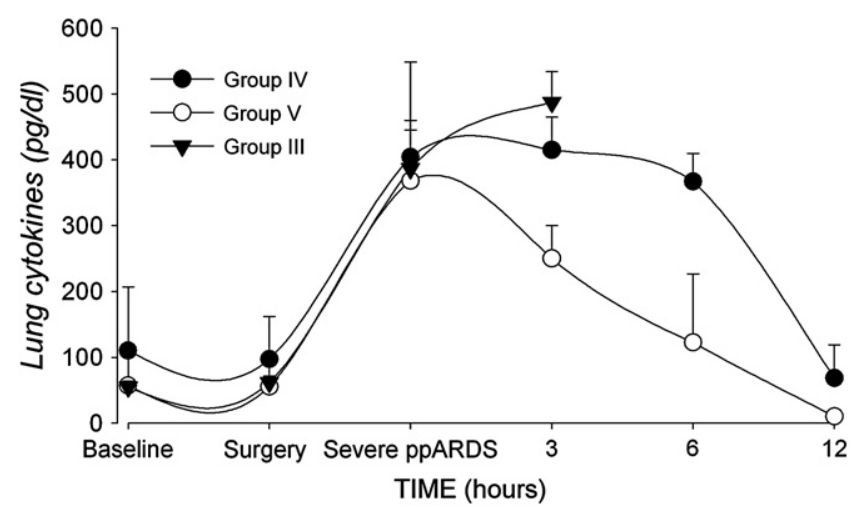

Figure 4. Dynamic of lung cytokines during the treatment periods in pigs with a post-pneumonectomy acute respiratory distress syndrome (ppARDS) observed only (group III), treated with conventional therapy (group IV), or extracorporeal lung membrane (iLA) and near-static ventilation (group V). Lung cytokines dropped during treatment and not during observation (pig survival, $3 \pm 1$ hours); however, only in iLA-treated pigs the cytokines returned within normal range $(P<.05)$ and not in pigs belonging to group IV (10 \pm 2 hours). The survival of pigs treated with iLA support in combination with near-static ventilation was $80 \%$ and fulfilled the extubation criteria $(\boldsymbol{P}<.01)$. Normal concentrations ranges in our laboratory are as follows: TNF- $\alpha(25-120 \mu \mathrm{g} / \mathrm{mL})$, IL-6 ( $<39 \mu \mathrm{g} /$ $\mathrm{mL})$, and IL-8 ( $<62 \mu \mathrm{g} / \mathrm{mL})$. 


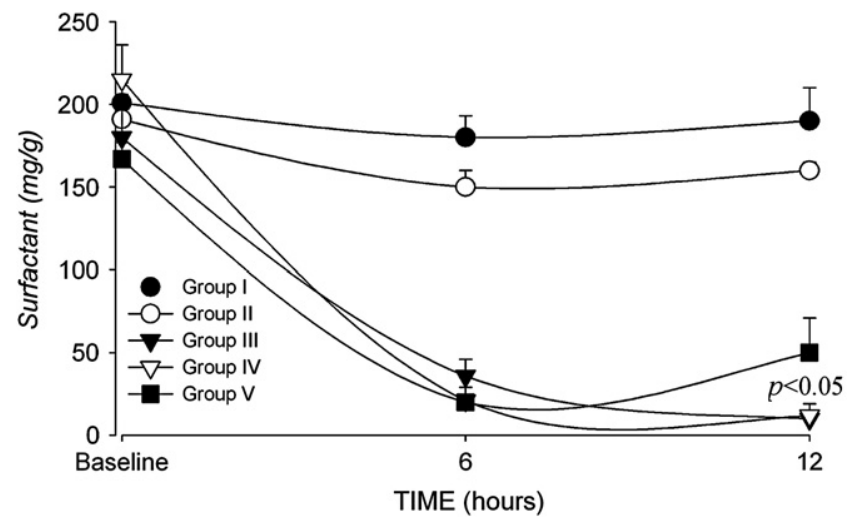

Figure 5. Dynamic of the surfactant level in the right lung managed with a postpneumonectomy acute respiratory distress syndrome. There was a significant $(P<.05)$ recovery of surfactant alveolar levels at 12 hours in iLA- treated pigs (group V) compared with the conventional treatment (group III).

confirmed by the analysis of the postmortem specimen of the right lungs of pigs receiving a surfactant-depletion ppARDS left untreated, where extensive exudative interstitial and alveolar lesions were noticed and responsible for the lung inflammation reactions. The possibility that standard MV (tidal volume $10-12 \mathrm{~mL} / \mathrm{kg}$; minute volume $10 \mathrm{~L} / \mathrm{min}$ ) could have amplified the induced ppARDS may be extrapolated from the unchanging expression of inflammatory mediators in the BAL fluid of ppARDS lungs treated with standard MV settings alone. All this evidence reinforces previous experimental and clinical observations that (1) the genesis of lung injury in acute lung injury/ARDS is multifactorial but once established involves the complex interplay of proinflammatory and antiinflammatory mediators ${ }^{9,10}$ and (2) MV can both induce and/or amplify lung injury because of the myriad of interactions between the mechanical ventilator, inspired oxidizing gazes, inflammatory mediators, and the lung. ${ }^{11-13}$

During primary acute lung injury/ARDS, the oxygenation failure is almost completely the result of the loss of aerated lung volume owing to atelectasis formation, mainly in the dependent lung areas, and therefore the formation of an intrapulmonary shunt. Consistently, the reopening of those atelectasis areas results in an improved gas exchange. Therefore, it has been the aim of numerous therapeutic strategies to recruit these otherwise nonventilated lung zones. Although MV with PEEP is lifesaving and without alternative in many of these patients, it has become more and more obvious during recent years that MV as such can contribute to or even promote lung damage, especially when high pressures and volumes are used, which often seems necessary to restore oxygenation. Accordingly, lung protective ventilation strategies have been developed that in general should avoid further lung damage by reducing tidal volume and distending airway pressure during MV. These strategies obviously might not necessarily be used to restore gas exchange to normal values. However, outcome studies have clearly shown that it is more essential to protect the lung from further damage than to normalize blood gas values. ${ }^{14}$

Lung protective ventilation strategies all substantially reduce alveolar ventilation by decreasing tidal volume and plateau pressure, and some of them also reduce respiratory frequency. There is currently a large body of evidence that reduction of tidal volume and distending pressures significantly improves clinical outcome in acute lung injury/ARDS. ${ }^{14}$ The resulting carbon dioxide retention either may be left untreated, as during permissive hypercapnia, ${ }^{15}$ or may be offset totally or in part by extracorporeal support with lung membrane ${ }^{16}$ or by washing the dead space with fresh gas delivery into the trachea. ${ }^{17}$ Extracorporeal gas exchange devices focus on carbon dioxide removal and oxygen exchange, avoid high tidal volume and airway pressure, and provide temporary or permanent respiratory life support even in the absence of native pulmonary function. ${ }^{18}$ Extracorporeal membrane oxygenator technology is the most widely known and used clinically ${ }^{19}$ and involves placing patients on a venovenous or venoarterial life support circuit with a membrane oxygenator to temporarily take over the gas exchange function of the lung. During extracorporeal life support, the mechanical ventilator settings can be reduced enough to reach nondamaging settings, thereby minimizing ventilatory-induced lung injury and maximizing both the recruitment of functional residual lung capacity and the rest and healing of the residual injured lungs. It has become the standard treatment of neonatal and pediatric respiratory failure unresponsive to other modes of treatment. ${ }^{20-22}$ Hemmila and associates ${ }^{23}$ have very recently provided definitive evidence that extracorporeal life support is a successful therapeutic option, even for adult patients with severe $\left(\mathrm{PaO}_{2} / \mathrm{FIO}_{2}<100\right)$ ARDS unresponsive to conventional mechanical ventilator strategies. However, its use has not gained wide acceptance, probably because of lack of evidence and randomized trials, fear about the related complications that are the rule and not the exception, team training, and costs. ${ }^{19}$

The extracorporeal lung membrane iLA used in this experimental study has, however, several advantages over other pump-driven devices. First, the iLA holds a very lowresistance $(\sim 7 \mathrm{~mm} \mathrm{Hg}$ at blood flow of 0.5 to $2.5 \mathrm{~L} / \mathrm{min}$ ) gas exchanger that requires only $20 \%$ to $30 \%$ of the $\mathrm{CO}$ as a unique driving force when placed via a simple peripheral percutaneous arteriovenous shunt to achieve extracorporeal near-total carbon dioxide removal. Therefore, any roller pump, a substantial portion of the tubing, and components related to the extracorporeal membrane oxygenator are unnecessary and potential related deleterious effects of foreign surface areas, priming fluid, and blood transfusion volumes ${ }^{24}$ are avoided. Moreover, all the tubing and membrane have a biologically active inner surface preventing local activation of the clotting system; as a result, no systemic anticoagulation 
more than routine thrombosis prophylaxis is necessary. Second and third, since the iLA allows an extracorporeal near-total carbon dioxide removal, the lungs are no longer required to supply a ventilatory function and can therefore be minimally ventilated (eg, $<4 \mathrm{mg} / \mathrm{mL}$ ). This is a condition sine qua non not only to obtain a minimal but sufficient "native" oxygenation via apneic oxygenation but also to put the damaged lungs at rest and give time to heal, according to the rationales behind extracorporeal carbon dioxide removal and apneic oxygenation elaborated by Kolobow, ${ }^{17}$ Gattinoni, ${ }^{16}$ and their associates.

All these theoretical hypotheses were recently used at the bedside of patients with severe ppARDS and unresponsive to standard conventional treatment, including conventional protective ventilation; the arteriovenous femoral placement was well tolerated and was able to reduce the pulmonary morbidity of the residual lung and improve the patient's outcome. ${ }^{3}$ This present experimental study was started in parallel with that clinical experience to compare, in attendance of a large clinical trial whose difficulties to set up could be imagined, standard protective ventilation with a maximal alveolar ventilation in ppARDS obtained via iLA and near-static ventilation. The severity of the surfactant-depletion ppARDS did not differ among groups in terms of gas deterioration, hemodynamic parameters, lung mechanics, or inflammatory response of the injured lung. There were, however, significant outcome differences among the groups in several respects. All ppARDS animals treated with standard ventilatory settings (tidal volume $10-12 \mathrm{~mL} / \mathrm{kg}$; minute volume $10 \mathrm{~L} /$ min) died within $3 \pm 1$ hours as a result of unresponsive and progressive respiratory failure. This may be explained by the double-edged sword effect of MV owing to the previously mentioned mechanisms. Animals with a ppARDS receiving conventional treatment including standard protective ventilation had significantly more pulmonary morbidity and poorer outcome (weaning and survival) than those treated with iLA and near-static ventilation. Probably, this may be explained by the fact that the iLA guaranteed not only sufficient gas exchange, $\mathrm{AVCO}_{2} \mathrm{R}$, and tissue oxygenation but, most important, a near-static ventilation (minute volume, $1.1 \pm 0.7 \mathrm{~L} / \mathrm{min}$ ), which minimized any further ventilatory-induced injury of the injured residual lung. Under this more protective status, the injured lungs were able to rest and heal, as documented by the significantly lowered pulmonary morbidity observed in iLA-treated pigs, for example, attenuation of lung cytokines and restoration of surfactant levels. This last restoration was probably the result of an active process, for example, de novo production or secretion of surfactant, because it is widely known that MV may inactivate surfactant and increase alveolar surface tension. ${ }^{8}$

In conclusion, these animal model-based observations reinforce our recent clinical findings regarding the advantages of extracorporeal respiratory support in ppARDS. They reveal that a protective ventilation strategy, including a pumpless extracorporeal lung membrane and alveolar hypoventilation, assures adequate gas exchange and affords more protection of the injured residual lung than standard protective ventilation. This in turn results in lower pulmonary morbidity and better outcome. The detailed mechanisms underlying these finding remain elusive and are likely multiple, including less ventilatory-induced injury to the residual injured lung, attenuation of the pulmonary inflammation, and regeneration of surfactant.

\section{References}

1. Lee HS, Lee JM, Kim MS, Kim HY, Hwangbo B, Zo JI. Low-dose steroid therapy at an early phase of postoperative acute respiratory distress syndrome. Ann Thorac Surg. 2005;79:405-10.

2. Mathisen DJ, Kuo EY, Hahn C, Moncoure AC, Wain JC, Grillo HC, et al. Inhaled nitric oxide for adult respiratory distress syndrome after pulmonary resection. Ann Thorac Surg. 1998;66:1894-902.

3. Iglesias M, Martinez E, García S, Sanchez D, Rodríguez A, Jungebluth P, et al. Extrapulmonary ventilation for unresponsive severe acute respiratory distress syndrome after pulmonary resection. Ann Thorac Surg. 2008;85:237-44.

4. Lachmann B, Robertson B, Vogel J. In vivo lung lavage as an experimental model of the respiratory distress syndrome. Acta Anaesthesiol Scand. 1980;24:231-6.

5. Matthay MA. Conference summary: acute lung injury. Chest. 1999; 116(Suppl 1):119S-26S.

6. Murray JF, Matthay MA, Luce JM, Flick MR. An expanded definition of the adult respiratory distress syndrome. Am Rev Respir Dis. 1988;138: 720-3.

7. Kloot TE, Blanch L, Melynne Youngblood A, Weinert C, Adams AB, Marini JJ, et al. Recruitment maneuvers in three experimental models of lung injury. Am J Respir Crit Care Med. 2000;161:1485-94.

8. Dreyfuss D, Saumaon G. Ventilator-induced lung injury. Lessons from experimental studies. Am J Respir Crit Care Med. 1998;57:294-323.

9. Fulkerson WJ, MacIntrye N, Stamler J, Crapo JD. Pathogenesis and treatment of the adult respiratory distress syndrome. Arch Intern Med. 1996; 156:29-38.

10. Jordan S, Mitchell JA, Quinlan GJ, Goldstraw P, Evans TW. The pathogenesis of lung injury following pulmonary resections. Eur Respir J. 2000;15:790-9.

11. Ranieri VM, Suter PM, Tortorella C, Tullior DC, Dayer JM, Brienza A, et al. Effect of mechanical ventilation on inflammatory mediators in patients with acute respiratory distress syndrome: a randomized controlled trial. JAMA. 1999;282:54-61.

12. Chollet-Martin S, Jourdain B, Elbim GC, Chastre J, GougerotPocidalo MA. Interactions between neutrophils and cytokines in blood and alveolar spaces during ARDS. Am J Respir Crit Care Med. 1996; 154:594-601.

13. Chiumello D, Prostine G, Slutsky A. Mechanical ventilation affects local and systemic cytokines in an animal model of adult respiratory distress syndrome. Am J Respir Crit Care Med. 1999;160:109-16.

14. The Acute Respiratory Distress Syndrome Network. Ventilation with lower tidal volumes as compared with traditional tidal volumes for acute lung injury. N Engl J Med. 2000;342:1301-8.

15. Hickling KG, Henderson SJ, Jackson R. Low mortality associated with low volume pressure limited ventilation with permissive hypercapnia in severe adult respiratory distress syndrome. Intensive Care Med. 1990; 16:372-7.

16. Gattinoni L, Pesanti A, Mascheroni D. Low-frequency positive-pressure ventilation with extracorporeal $\mathrm{CO} 2$ removal in severe acute respiratory failure. JAMA. 1986;256:881-6.

17. Kobolow T, Powers T, Mandara S, Aprigliano M, Kwaguchi A, Tsuno K, et al. Intratracheal pulmonary ventilation (ITPV): control of positive end-expiratory pressure at the level of the carina through the use of a novel ITPV catheter design. Anesth Analg. 1994;78:455-61.

18. Morris AH, Wallace CJ, Menlove RL, Clemmer TP, Orme JF Jr, Weaver LK, et al. Randomized clinical trial of pressure controlled inverse 
ration ventilation and extracorporeal $\mathrm{CO} 2$ removal for adult respiratory distress syndrome. Am J Respir Crit Care Med. 1994;149:295-305.

19. Alpard SK, Zwischenberger JB. Extracorporeal membrane oxygenation for severe respiratory failure. Chest Surg Clin N Am. 2002;12:355-78.

20. Bartlett RH, Roloff DW, Cornell RG, Andrews AF, Dillon PW, Zwischenberger JB. Extracorporeal circulation in neonatal respiratory failure: a prospective randomized study. Pediatrics. 1985;76:479-87.

21. Bartlett RH, Roloff DW, Custer JR, Younger JG, Hirschl RB. Extracorporeal life support: the University of Michigan experience. JAMA. 2000; 283:904-8.

22. Swaniker F, Kolla S, Moler F, Custer J, Grams R, Barlett R, et al. Extracorporeal life support outcome for 128 pediatric patients with respiratory failure. J Pediatr Surg. 2000;35:197-202.

23. Hemmila MR, Rowe SA, Boules TN, Miskulin J, McGillicuddy JW, Schuerer DJ, et al. Extracorporeal life support for severe acute respiratory distress syndrome in adults. Ann Surg. 2004;240:595-605.

24. Alpard SK, Zwischenberger JB, Tao W, Deyo DJ, Bidani A. Reduced ventilator pressure and improved $\mathrm{P} / \mathrm{F}$ ratio during percutaneous arteriovenous carbon dioxide removal for severe respiratory failure. Ann Surg. 1999;230:215-24.

\section{Discussion}

Dr Bartley P. Griffith (Baltimore, $M d$ ). Dr Iglesias and Dr Macchiarini, I thank you for what may be a paradigm-shifting manuscript that may in fact change practice to a great degree in this terrible postoperative complication.

[Slides] Some time ago I was interested in the laboratory with pursuing arteriovenous extracorporeal membrane oxygenation as an artificial placenta to mature newborn lamb lungs. We did not recognize then the importance of barotrauma, and we evaluated the shunt required to normalize $\mathrm{Po}_{2}$. We early learned that by increasing the shunt, we could change $\mathrm{Po}_{2}$, but the numbers required to do that required a great strain on the heart.

The importance of this paper has been to confirm the concept that Gattinoni brought to us of the "baby lung." We must remember the ARDS patient shown on this computed tomographic scan, the importance of the defunctionalized lung that does not ventilate as opposed to the ventilated lung, which may be as little as a third of each lung. Sixty-six percent of this patient's lung would not be ventilated and $33 \%$ would be ventilated, so even at a reserved low-volume ventilation, that translates into about $18 \mathrm{~mL} / \mathrm{kg}$ or high ventilation volume to the normally ventilated lung, which we know from ARDSNet to be counterproductive.

You have appropriately dissociated oxygenation and MV. Extrapulmonary gas exchange replaces MV, which enables a therapeutic window to protect the ventilation. The key to your study, of course, is the low-resistance oxygenator that is now commercially available in Europe and the fact that less than $20 \%$ of the $\mathrm{CO}$ needs to be diverted into this oxygenator to achieve almost $300 \mathrm{~mL}$ of carbon dioxide removal. While you ventilated with a PEEP of 19, your end-inspiratory pressure was only 21 . Your tidal volume was a third of the "optimized" ventilated group and a fifth of the conventionally ventilated group. Your minute volume was only $1 \mathrm{~L}$, at a rate of 6 . Your model probably is not the same that we see clinically with
ppARDS, but that is okay. I think what you have demonstrated is lung protection, which is the hallmark of treating this terrible problem.

I have two questions for you. Have you looked at various forms of ventilation of your animals that might in fact even improve on the outcomes that you had with the current experimental group? In other words, have you tried continuous positive airway pressure as a ventilatory method for these animals, extubating them very early?

Finally, have you measured cytokines in animals that did not have anything other than the iLA associated with it? Early on in my career, there was a lot of criticism about using artificial lung membranes in patients with injured lungs for fear that cytokines would in fact be elaborated.

Dr Iglesias. Thank you for your questions. To address the second question, I performed a study accepted in the Journal of Thoracic and Cardiovascular Surgery where we placed the iLA in axillary vascular access and then we measured the cytokine response and did not find a systemic inflammatory response in this type of pigs. It was done undergoing nothing for us. It practically inhaled the pigs.

I did not understand your first question.

Dr Griffith. Could you forecast perhaps an even better form of assisted ventilation to work in concert with the iLA, such as spontaneous continuous positive airway pressure?

Dr Iglesias. I refer this question to Dr Macchiarini.

Dr Macchiarini. Thank you for the question. Yes, we did, in the sense that as soon as you get on the iLA, you need to adapt the ventilation and try the best setting in the sense that some respond very well to pressure control and some to volume control. We found that for the type of pneumonectomy that we did, a very simple pneumonectomy, the pressure control ventilation was the simplest to manage. Whether or not this was because we had such a high level of PEEP, I cannot tell you that, but it is a little bit parallel to what we saw in the clinical experience on severe ppARDS. I would suggest that from the experimental and clinical experience, so long as you reach the target to reduce the tidal volumes as low as you can, you might use either of the ventilation modes. We can go even further. We tried to not ventilate the patients at all in the clinical setting but simply keeping in place the tracheostomy tube or the tracheal tube and putting a very low flow of oxygen, doing a sort of apneic oxygenation. It did work as well. So there is a very large variability among patients. You might try to use the best one adapted to the patient, as long as you reach very low tidal volumes.

Dr Nasser K. Altorki (New York, NY). How long were the pigs generally treated on the extracorporeal membrane oxygenator? Were they also on some ancillary measures, such as steroids, or were they just treated simply by the oxygenator?

Dr Iglesias. We treated with iLA in a total of 5 pigs among the 15 pigs in which we induced ARDS by surfactant depletion.

Dr Altorki. How many days were they on it after the ARDS induction?

Dr Iglesias. Ninety minutes, more or less. 

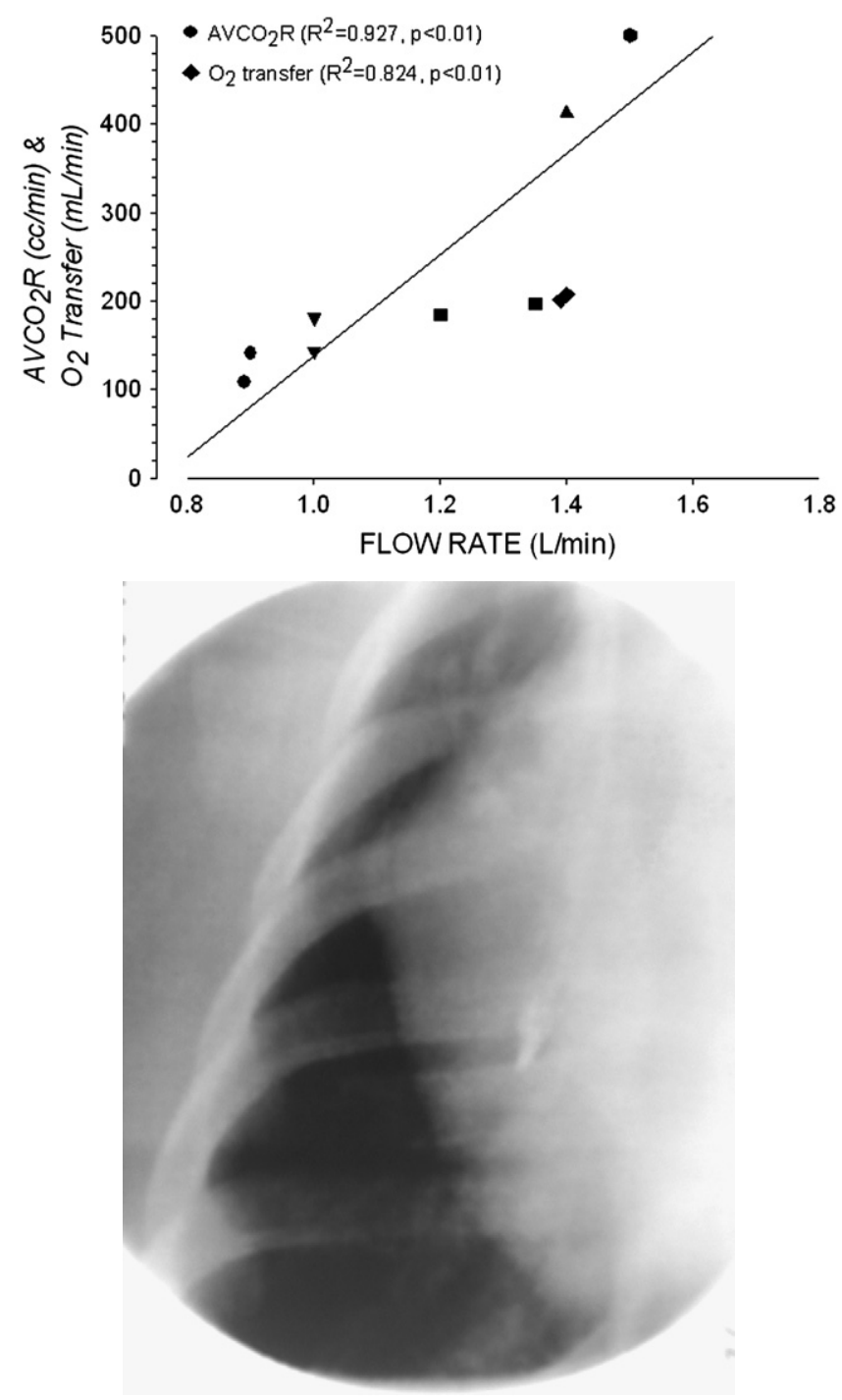

Figure E1. Correlation of oxygen $\left(\mathrm{O}_{2}\right)$ transfer and arteriovenous carbon dioxide $\left(\mathrm{CO}_{2}\right)$ removal $\left(\mathrm{AVCO}_{2} \mathrm{R}\right)$ to the blood flow perfusing the iLA device. 
TABLE E1. Histologic grading of the severity and extension of the lesions observed at postmortem examination in the right lung

\begin{tabular}{|c|c|c|c|c|}
\hline \multirow{2}{*}{$\begin{array}{c}\text { Severity score grading } \\
\text { Histopathologic findings }\end{array}$} & \multirow[b]{2}{*}{ Absent } & \multirow[b]{2}{*}{ Mild } & \multirow[b]{2}{*}{ Moderate } & \multirow[b]{2}{*}{ Severe } \\
\hline & & & & \\
\hline Atelectasis & 0 & 1 & 2 & 3 \\
\hline $\begin{array}{l}\text { Bronchial epithelium } \\
\text { desquamative }\end{array}$ & 0 & 1 & 2 & 3 \\
\hline Hyaline membranes & 0 & 1 & 2 & 3 \\
\hline Exudative interstitial lesions & 0 & 1 & 2 & 3 \\
\hline Exudative alveolar lesions & 0 & 1 & 2 & 3 \\
\hline Extension score grading & Focal & & Itifocal & Diffuse \\
\hline Extension of ARDS lesions & 1 & & 2 & 3 \\
\hline
\end{tabular}


TABLE E2. Hemodynamic and lung permeability differences in ppARDS pigs observed only (group III), treated with protective ventilation (group IV) or extracorporeal lung membrane (iLA) support (group V)

\begin{tabular}{|c|c|c|c|c|}
\hline Variables & Group III & Group IV & Group V & $P$ value \\
\hline CO (L/min) & $5.3 \pm 1$ & $5.8 \pm 1$ & $5.5 \pm 1^{*}$ & $<0.05$ \\
\hline $\mathrm{MAP}(\mathrm{mm} \mathrm{Hg})$ & $80 \pm 22$ & $77 \pm 6$ & $64 \pm 4^{*}$ & 0.001 \\
\hline MPAP $(\mathrm{mm} \mathrm{Hg})$ & $44.1 \pm 8$ & $38.6 \pm 7.9$ & $42.6 \pm 5.3$ & NS \\
\hline SVR (Dyne/cm ${ }^{5}$ ) & $1177 \pm 526$ & $791 \pm 168$ & $650 \pm 178^{*}$ & 0.001 \\
\hline PVR (Dyne/cm ${ }^{5}$ ) & $451 \pm 117$ & $325 \pm 113$ & $301 \pm 109^{*}$ & 0.03 \\
\hline PCWP (mm Hg) & $14 \pm 8$ & $19 \pm 1$ & $17 \pm 4^{*}$ & 0.001 \\
\hline CVP $(\mathrm{mm} \mathrm{Hg})$ & $13 \pm 7$ & $21 \pm 0.4$ & $21 \pm 2^{*}$ & 0.01 \\
\hline $\operatorname{Dpmax}(\mathrm{mm} \mathrm{Hg})$ & $700 \pm 283.3$ & $763.7 \pm 321.9$ & $1029 \pm 422.5^{*}$ & 0.01 \\
\hline ELWI (mL/kg) & $12 \pm 2$ & $13 \pm 5$ & $21 \pm 14^{*}$ & 0.01 \\
\hline
\end{tabular}

ppARDS, Postpneumonectomy acute respiratory distress syndrome; $C O$, cardiac output; $M A P$, mean arterial pressure; MPAP, mean pulmonary arterial pressure; $S V R$, systemic vascular resistance; $R V P$, pulmonary vascular resistance; $P C W P$, pulmonary capillary wedge pressure; $C V P$, central venous pressure; Dpmax, ventricular contractibility, ELWI, index extra lung volume water; $N S$, not significant. *Comparison between groups V and III/IV. 
TABLE E3. Kinetic of the lung cytokines over time in ppARDS treated with conventional treatment (group IV) and extracorporeal lung membrane (iLA) support and near-static ventilation (group V)

\begin{tabular}{llcccrr}
\hline Cytokines & Group & Baseline & Pneumonectomy & ppARDS & 6-h ppARDS & 12-h ppARDS \\
\hline TNF- $\alpha$ & IV & $119 \pm 17$ & $102 \pm 18$ & $461 \pm 23$ & $319 \pm 20$ \\
& V & $82 \pm 12$ & $71 \pm 68$ & $540 \pm 121$ & $65 \pm 15$ & $126 \pm 11$ \\
IL-6 & IV & $9 \pm 2$ & $30 \pm 15$ & $386 \pm 125$ & $384 \pm 35$ & $20 \pm 5^{*}$ \\
& V & $2 \pm 1$ & $10 \pm 4$ & $384 \pm 55$ & $243 \pm 20$ & $50 \pm 17$ \\
IL-8 & IV & $20 \pm 3$ & $16 \pm 8$ & $365 \pm 143$ & $399 \pm 30$ \\
& V & $89 \pm 19$ & $85 \pm 17$ & $180 \pm 12$ & $60 \pm 8$ \\
\hline
\end{tabular}

ppARDS, Postpneumonectomy acute respiratory distress syndrome; TNF- $\alpha$, tumor necrosis factor $\alpha$; $I$, interleukin. ${ }^{*}$ Denotes statistical significance at $P<.05$. 